\title{
Impact of a Peer Public Health Education Programme on Adolescent Students' Knowledge of HIV/AIDS and Attitude Towards People Living with HIV/AIDS in Abia State, South East Nigeria
}

\author{
${ }^{1}$ Ursula Chigozie Nnabueze, ${ }^{2}$ Liesl Nydegger, ${ }^{3}$ Ijeoma Ogwe Onuoha, ${ }^{* 4}$ Tochi Emmanuel Iwuagwu \\ ${ }^{1}$ Department of Health and Physical Education, Enugu State University of Science \& Technology (ESUT) \\ Enugu, Nigeria \\ ${ }^{2}$ Department of Kinesiology and Health Education, University of Texas at Austin \\ ${ }^{3}$ United Nations Children's Fund (UNICEF) Office, Abuja Nigeria \\ ${ }^{4}$ Department of Human Kinetics and Health Education, University of Nigeria, Nsukka, Enugu State, Nigeria \\ *E-mail of the corresponding author: tochi.iwuagwu@unn.edu.ng; +2348063290746
}

\section{Abstract \\ Background}

The scourge of HIV/AIDS remains one of the contemporary challenges facing Nigeria and numerous other subSaharan countries. We assessed the impact of a peer public health education programme on adolescent students' knowledge of HIV/AIDS and attitude towards People Living with HIV/AIDS in Abia State, South East Nigeria.

Materials and Methods

In a quasi-experiment adopting pretest and posttest comparison group, a total number of 156 (74 male and 82 female) Junior Secondary School Students three (JSS3) participated. Data collection was done using selfstructured HIV/AIDS Knowledge Test (HAKT) and HIV/AIDS Attitude Scale (HAAS). Mean, standard deviation and analysis of covariance were used for analyses.

Results

The findings reveal that the adolescent students who were given the peer education training attained higher knowledge of HIV/AIDS and also showed greater positive attitude towards people living with HIV/AIDS.

Conclusion

This research proves that peer education training is evidenced in attaining higher knowledge of HIV/AIDS and in showing greater positive attitude towards people living with HIV/AIDS. However, peer education training should be adopted as one of the teaching modes in schools, which will enhance good HIV/AIDS knowledge and positive attitudinal disposition towards people living with HIV/AIDS.

Keywords: Peer public health education, HIV/AIDS, People living with HIV/AIDS, Adolescents, Knowledge, Attitude

DOI: $10.7176 / \mathrm{JHMN} / 93-06$

Publication date:September $30^{\text {th }} 2021$

\section{Introduction}

The scourge of HIV/AIDS remains one of the contemporary challenges facing Nigeria and numerous other subSaharan countries. Nigeria has the second largest HIV epidemic in the world [1]. Recent statistics from 2018 revealed that although HIV prevalence among adults is much less in Nigeria $(1.5 \%)$ than other sub-Saharan African countries, such as: South Africa (20.4\%) and Zambia (11.3\%), in Nigeria's population there were 1.9 million people living with HIV in 2018. This interprets to a reduction from 3.1 million in 2017 [2], yet young people are still disproportionately affected by HIV/AIDS.

Available statistics estimate that in 2017, approximately two-thirds of new HIV infections that were in West and Central Africa occurred in Nigeria [3]. Despite achieving a significant reduction in new infections within seven years (2010 and 2017), Nigeria, together with South Africa and Uganda, have been reported to have accounted for around half of all new HIV infections in sub-Saharan Africa every year [4].

[3] identified young people as one of the groups most affected by HIV/AIDS. [5]reported that in 2016, 240,000 adolescents between the ages of 10-19 were living with HIV, making up 7\% of the total number of people with HIV in Nigeria. Lack of knowledge has been identified as one of the factors that increase HIV vulnerability among young people [3]. 
According to [6], global success in combating HIV/AIDS must be measured by its impact on our children and young people. Special priority to young people, especially using education, will change the future course of the epidemic in Nigeria and other affected sub-Saharan countries. Changing behaviours and expectations early will result in a lifetime benefit - both in HIV prevention and in overcoming HIV-related stigma. The challenge is to promote effective programmes that engage young people in all aspects of the response to HIV/AIDS. One of such programmes is peer health education.

Education stands out as one of the most effective tools to combat the menace of HIV/AIDS in the $21^{\text {st }}$ century. Educating young people about HIV/AIDS and teaching them skills in negotiation, conflict resolution, sex and sexuality, critical thinking, decision-making, and communication will help improve their self-confidence and ability to make informed decisions, such as: postponing sex until they are mature enough to protect themselves from HIV, other STIs and unwanted pregnancies. We purport that the knowledge and attitude of Nigerian youth towards HIV/AIDS will be positively improved with peer education.

Gallant and Maticka-Tyndale in [7] reported that school-based HIV/AIDS health education may be an effective way to prevent the spread of HIV among adolescents and youth. It has been a cornerstone of youth-focused HIV prevention efforts since the early1990s [8]. In order to maintain healthy sexual behaviours, change of risky sexual behaviours, and modify norms, peer-led HIV intervention that involve members of a specific at-risk group are thought to be more effective [9]. In addition, compared to professional health care providers, using peer educators is less expensive.

Peer education is a strategy in which individuals from a target group provide information, training, or resources to their peers. The groups can be determined by social or demographic characteristics (e.g., age, education, type of work) or by risk-taking behaviour[7]. Peer education has been a popular method of health education for HIV prevention since 1980s, perhaps because of the positive interaction it brings between peers (Kindeberg and Christensson, in [7]). Generally, peer education is a low-cost and widely used intervention for HIV prevention, especially among young populations. The goal of peer education is to develop knowledge, attitudes, beliefs, and skills needed to engage in healthy behaviours. Globally, peer education has been widely used as a strategy to address the HIV/AIDS pandemic as an approach in communicating behavioural change [10].

In Nigeria, members of the National Youth Service Corps (NYSC) are mostly trained to serve as peer educators. Youth corps members are Nigerian graduates who are on a one-year compulsory national service. Usually, these graduates, mainly holders of first degree and Higher National Diploma (HND) are posted on this selfless and paramilitary service outside their states of origin (except for some obvious reasons), to promote national unity. Corps members can be change agents if their talents, youthful and exuberant energies are properly channeled through a peer education programme. They are provided with scientifically accurate and culturally sensitive information on HIV/AIDS for their own benefits first, and for sharing with other young people, including secondary school students and the larger population.

Peer health education for combating HIV/AIDS has become imperative in Abia State, which was listed to have a prevalence rate of $2.1 \%$ in 2019 . This is higher than the current national prevalence rate of $1.4 \%$ [ 11 ]. According to [2], there has been progress in the number of AIDS-related deaths since 2010, with a $26 \%$ decrease, from 72,000 deaths to 53,000 deaths. The number of new HIV infections has risen, however, from 120,000 to 130,000 in the same period. This increase in HIV infection rates demonstrates that more HIV prevention interventions are essential, creating awareness and curbing the spread of the epidemic. Recruiting NYSC members to serve as peer educators for HIV/AIDS will play a positive role in achieving the desired result.

The ravages of HIV and AIDS on the Nigerian population are becoming very evident since the first case was reported in 1986. HIV infection among the sexually active population grew from $1.8 \%$ in 1991 to $5.8 \%$ in 2002 [12]. With lack of correct knowledge of reproductive health regarding adolescent health among young people, the growth of HIV infection has reached the exponential phase with catastrophic developmental and social consequences.

Sero-prevalence surveys reveal that young people are at the centre of the HIV/AIDS epidemic, and contribute about $40 \%$ of all new HIV infections globally [13]. They are the group at highest risk of HIV infection. Infection rates among the population segment below 15 years are also growing rapidly. The survival and development of future leaders in Nigeria seem doomed unless there are dramatic and drastic efforts at increasing reproductive 
health knowledge and reversing the negative attitudes that lead to the rapid spread of HIV/AIDS resulting in this epidemic.

Perhaps, the introduction of health education as a subject in the Nigerian school system will be a giant stride in the attempt to increase the knowledge of our youths on HIV/AIDS awareness. However, the impact so far seems to be insignificant; hence, the emergence of so many intervention programmes with little evaluation of their effectiveness.

Unfortunately, researchers and educators have not given the much desired attention to the peer education programme. Evidently, limited research has been conducted on the peer education programme. The current study addresses this gap in the literature. In view of these facts, the study investigated the impact of a peer health education programme on students' knowledge of HIV/AIDS and attitude towards PLWHAS. Specifically, the study determined: significant difference between HIV/AIDS knowledge scores of students given the peer education training and their counterparts taught the same topics without peer education training; significant difference between PLWHAS attitude scores of students given the peer education training and their counterparts taught the same topics without peer education training; significant difference between HIV/AIDS knowledge scores of male and female students given the peer education training and their counterparts taught the same topics without peer education training; and significant difference between PLWHAS attitude scores of male and female students given the peer education training and their counterparts taught the same topics with peer education training.

\section{Materials and Methods}

\section{Study design and setting}

The design of the study was quasi-experimental. Specifically, the study adopted pretest posttest non-equivalent comparison (control) group design. The study was conducted in Umuahia metropolis, among Junior Secondary School three (JSS3) students. Umuahia metropolis is the capital of Abia State, Nigeria, which is comprised of two local government areas: Umuahia North and Umuahia South. The area was chosen for the study due to its large population of youth.

\section{Participants}

The study participants consisted of all the 2,340 JSS3 students in the 18 public secondary schools in the study area [14]. Out of this population, 1,224 were males while 1,116 were females. JSS3 students were chosen for the study as they were considered to having been more exposed to HIV/AIDS information through health education classes and also more aware of societal happenings than their counterparts in other Junior classes [15].

\section{Sampling procedures}

A sample size of 156 JSS3 students, consisting of 82 female and 74 male students were used for the study. From the two local government areas that make up Umuahia metropolis, the researcher sampled two schools each by simple balloting. From each of the four schools sampled, simple balloting was also used to sample one intact JSS3 class. From each of the four classes, students were allowed to voluntarily opt for peer education training. Names of students who indicated interest were taken, and they joined the peer education training serving as the experimental group. Summarily, 72 students joined the peer education training and were used as experimental group while the remaining 84 students did not join the training and were thus used as control group.

\section{Material and measures}

The instruments used for data collection comprised the HIV/AIDS Knowledge Test (HAKT) and HIV/AIDS Attitude Scale (HAAS). Both instruments were developed by the first author; HAKT, made up of 33 multiple choice questions while HAAS consisted of 20 items. The instruments were validated by three experts, one in health education and two in measurement and evaluation, from the Faculty of Education, Enugu State University of Science and Technology (ESUT) Enugu, Nigeria. HAKT yielded a reliability coefficient of 0.72 using Kudar Richardson's formula 20 (KR-20) while HAAS yielded reliability of coefficient of 0.81 using the Cronbach's Alpha coefficient.

\section{Data collection procedure}

The current research was developed in accordance with the Ethical Principles of the World Medical Association Declaration of Helsinki for medical research involving human subjects [16], and the research was approved by Research Ethics Committee of the Faculty of Education, University of Nigeria, Nsukka (UNN/FE/REC19/093). 
In order to obtain the participation of the subjects, the research team met with the Principals and school administrators of the various secondary schoolsselected for the study, requesting the participation of their students. After agreement with the Principals and other school personnel, informed consent was obtained from the students and the administration, and it was explained to them how and when the data would be taken. Also, the research team explained the objectives of research for the participants and the latter were assured about the privacy of their personal data.

Prior to treatment, pretest scores were collected from the subjects in the four schools using the instruments. After treatment, which lasted for six weeks, the items of the instruments were re-arranged randomly and readministered to all the subjects to collect the posttest scores.

\section{Data analysis}

The IBM Statistical Package for Social Sciences (SPSS) version 23.0 was used for all the statistical analyses. The standard descriptive statistics were applied to describe data pattern. Mean, standard deviation and analysis of covariance were used for analyses. The normality of the data was checked through skewness, kurtosis and the Kolmogorov-Smirnov (K-S) test. Normal distribution was considered if the skewness showed values between 2 and +2 , and the KS test is not significant [17]. In order to adjust the sample to normal, the data of each variable were adjusted using $\operatorname{In}(\mathrm{x})$ and $\mathrm{x}^{2}$ algorithms if they were not normally distributed. The internal consistency of the HAKT was estimated using Kudar Richardson's formula 20 (KR-20) while HAAS was estimated Cronbach's Alpha coefficient. All the tests were 2-tailed, and the probability values less than 0.05 $(\mathrm{p}<0.05)$ were considered significant.

Results

Table 1: Pretest and posttest HIV/AIDS mean knowledge scores and standard deviations of students in experimental and control groups

\begin{tabular}{|l|l|l|l|l|}
\hline Treatment & $\begin{array}{l}\text { Experimental } \\
(\mathbf{N = 7 2 )}\end{array}$ & $\begin{array}{l}\text { Control } \\
(\mathbf{N}=84\end{array}$ & p-value \\
\hline Pretest & Mean & 33.6 & 32.8 & .067 \\
\hline & SD & 8.5 & 8.2 & \\
\hline Posttest & Mean & 81.3 & 51.1 & $.010^{*}$ \\
\hline & SD & 3.2 & 9.4 & \\
\hline
\end{tabular}

For the control group, the pretest mean knowledge score and standard deviation were 32.8 and 8.2 , respectively, while the posttest were 51.1 and 9.4, respectively. Differences between pretest scores among groups were minimal (Table 1). While not statistically significant at pre-test $(p=.067)$, the differences between posttest scores was programmatically significant $(p=0.01)$; the experimental group scored much higher with a smaller standard deviation.

Table 2:Pretest and posttest PLWHAS mean attitude scores and standard deviations of students in experimental and control groups

\begin{tabular}{|l|l|l|l|l|}
\hline Treatment & & $\begin{array}{l}\text { Control } \\
\mathbf{( N = 8 4 )}\end{array}$ & $\begin{array}{l}\text { Experimental } \\
(\mathbf{N}=\mathbf{7 2})\end{array}$ & p-value \\
\hline Pretest & Mean & 41.7 & 41.6 & .059 \\
\hline & SD & 10.8 & 11.3 & \\
\hline Posttest & Mean & 50.1 & 69.7 & $.000^{*}$ \\
\hline & SD & 9.6 & 4.3 & \\
\hline
\end{tabular}

In the control group, the pretest mean attitude score and standard deviation were 41.7 and 10.8 respectively, while the posttest were 50.1 and 9.6 respectively. While there was a minimal difference between the attitude scores of the two groups before treatment, the pretest mean attitude scores and standard deviation showed remarkable differences (see Table 2). The experimental group had a significantly higher mean attitude score than the control group $(p=.000)$. 
Table 3: Pretest and posttest mean HIV/AIDS knowledge scores and standard deviation of male and female students in experimental and control groups

\begin{tabular}{|l|l|l|l|l|l|l|l|}
\hline Treatment & $\begin{array}{l}\text { Male } \\
\text { Control }\end{array}$ & Experimental & $\begin{array}{l}\text { p- } \\
\text { value }\end{array}$ & $\begin{array}{l}\text { Female } \\
\text { Experimental }\end{array}$ & Control & $\begin{array}{l}\text { p- } \\
\text { value }\end{array}$ \\
\hline Pretest & Mean & 32.3 & 31.7 & .063 & 31.6 & 32.1 & .072 \\
\hline & SD & 9.1 & 7.4 & & 9.4 & 8.2 & \\
\hline Posttest & Mean & 50.4 & 80.3 & $.000^{*}$ & 51.2 & 81.4 & $.012^{*}$ \\
\hline & SD & 8.3 & 4.1 & & 9.1 & 4.2 & \\
\hline
\end{tabular}

Table 3 demonstrates that males in the experimental group had a mean score of 31.7 and 80.3 in pretest and posttest respectively, while males in the control had 32.3 and 50.4 mean scores respectively. There was no statistically significant difference in the pretest mean scores between control and experimental groups $(p=.063)$, in the posttest males in the experimental group scored significantly higher than males in the control group ( $p$ value $=.000)$.

Similarly, there was no statistically significant difference between females in the experimental and control groups on the pretest $(p$-value $=.072)$. However, females in the experimental group scored significantly higher compared to females in the control group ( $p$-value $=.012$ ).

Table 4: Pretest and posttest mean PLWHAS attitude scores and standard deviation of male and female students in experimental and control groups

\begin{tabular}{|l|l|l|l|l|l|l|l|}
\hline Treatment & & $\begin{array}{l}\text { Male } \\
\text { Experimental }\end{array}$ & Control & $\begin{array}{l}\text { p- } \\
\text { value }\end{array}$ & $\begin{array}{l}\text { Female } \\
\text { Experimental }\end{array}$ & Control & $\begin{array}{l}\text { p- } \\
\text { value }\end{array}$ \\
\hline Pretest & Mean & 41.05 & 40.7 & .104 & 40.8 & 41.1 & .210 \\
\hline & SD & 10.8 & 9.6 & & 9.7 & 10.2 & \\
\hline Posttest & Mean & 68.3 & 49.5 & $.028^{*}$ & 68.7 & 50.1 & $.034^{*}$ \\
\hline & SD & 3.6 & 8.8 & & 4.1 & 9.4 & \\
\hline
\end{tabular}

From Table 4, the male students scored 41.05 and 40.7 in both experimental and control groups respectively while the females scored 40.8 and 41.1 respectively in the pretest. In the posttest, the male and female students in the experimental group recorded higher mean attitude scores than their contemporaries in the control group with 68.3 and 68.7 respectively as against 49.5 and 50.1 of the male and female control groups. There was no statistically significant difference between males in the experimental and control groups on the pretest $(p=.104)$. However, on the posttest, males in the experimental group score significantly higher their counterparts in the control group $(p=.028)$.

Similarly, there was no statistically significant difference between females in the experimental and control groups on the pretest $(p=.210)$. However, on the posttest, females in the experimental group score significantly higher their counterparts in the control group $(p=.034)$.

\section{Discussion}

The study revealed that the students taught with peer education training achieved higher scores on HIV/AIDS knowledge and positive attitude toward PLWHAS than their counterparts taught without peer education. Results demonstrated that there was no significant difference at pretest, and there was at posttest. This shows that the method of teaching is a major factor affecting increases in students' HIV/AIDS knowledge attainment.

The experimental group received peer education training in addition to the normal HIV/AIDS class lessons, which enhanced their knowledge of HIV/AIDS; while the comparison group received the normal HIV/AIDS class lessons. This supports [18] who reported that when the appropriate method is in use, there is a time for doing, time for reflection, time for feeling, and a time for assessment. Peer education training afforded students the opportunity of engaging in different learning activities. 
Also in support of the finding are the reports of $[19,20,21]$. They all held that peer education resulted to improved knowledge of HIV/AIDS. However, this finding deviated from those of [22] who found no significant difference in the HIV/AIDS knowledge attainment of peer educators and other students.

The results further showed no significant difference in the PLWHAS attitude scores of the experimental and control groups in the pretest. On the other hand, peer education training resulted to a significant difference in the attitude scores of students in the experimental and control groups, in favour of the experimental group. This finding is in line with the reports of [20, 23, 24]. However, it is contrary to [25] who reported that both educators and non-peer educators yielded no increased positive attitudes towards PLWHAS. Table 4 shows no significant effect of method and gender on students' mean knowledge scores of HIV/AIDS and attitude scores towards PLWHAS. This holds contrary to the findings of [26] that females exhibit better knowledge of HIV/AIDS than males. Results suggest that a peer health education programme can be utilized as a tool for improving students' knowledge of HIV/AIDS and attitude towards People Living with HIV/AIDS in Abia State.

\section{Conclusions}

Our findings have shown that students in the experimental group that were taught HIV/AIDS topics with peer education training achieved more HIV/AIDS knowledge than those taught without peer education training. Students in the experimental group showed more positive attitude towards HIV/AIDS than those in the control group. However, peer education training should be adopted as one of the teaching modes in schools. Teachers should receive assistance (sponsored) to learn the skills of peer education through seminars, workshops, and conferences so as to enhance HIV/AIDS knowledge and positive attitudinal disposition towards people living with HIV/AIDS. Government at all levels (federal, state, and local) should support a peer education programme financially and otherwise. More non-governmental organizations (NGOs) should be encouraged to invest in a peer education programme. National Youth Service Corps (NYSC) members who volunteer as peer educators should be paid extra allowance by the government as a way of encouraging them to participate in curbing the disease burden of HIV/AIDS.

\section{Acknowledgements}

We would like to express our sincere gratitude to the various schools and school administrators that permitted us to study their subjects. We sincerely appreciate all the adolescent students that participated in the study for their cooperation and provision of necessary information. We would also like to express our appreciation for the constructive review done by one anonymous reviewer that helped to improve the manuscript prior to submission.

\section{References}

1. National Agency for the Control of AIDS (NACA).National Strategic Framework on HIV and AIDS: 20172021. 2017. [Available at https://www.childrenandaids.org/sites/default/files/2017-11/NATIONAL-HIVAND-AIDS-STRATEGIC-FRAMEWORK.pdf [Accessed on 11 th December, 2020]

2. Joint United nations Programme on HIV/AIDS (UNAIDS).Country: Nigeria. 2019. [Available at https://www.unaids.org/en/regionscountries/countries/nigeria [Accessed on 11 th December, 2020]

3. Joint United nations Programme on HIV/AIDS (UNAIDS).Data book. 2017. [Available at https://www.unaids.org/sites/default/files/media_asset/20170720_Data_book_2017_en.pdf[Accessed on 11th December, 2020]

4. Avert. HIV and AIDS in Nigeria. 2019. [Available at https://www.avert.org/professionals/hiv-aroundworld/sub-saharan-africa/nigeria [Accessed on 11th December, 2020]

5. United Nations Children's Fund (UNICEF) (2017).Statistical tables.2017. [Available at https://data.unicef.org/topic/hivaids/global-regional-trends/[Accessed on 11th December, 2020]

6. World Health Organization.Education for all: a manual on health education in primary health care; 2004.

7. Menna T, Ali A, Worku A. Effects of peer education intervention on HIV/AIDS related sexual behaviors of secondary school students in Addis Ababa, Ethiopia: a quasi-experimental study. Reprod. Health. 2015; $12: 84$.

8. Medley A., Kennedy C, O’Reilly K, Sweat M. Effectiveness of peer education interventions for HIV prevention in developing countries: a systematic review and meta-analysis. AIDS Educ Prev. 2009; 21(3):181-206. 
9. Webel AR, Okonsky J, Trompeta J, Holzemer WL. A systematic review of the effectiveness of peer-based interventions on health-related behaviors in adults.Am J Public Health. 2010;100: 247-53.

10. Ali MHM, Osman OB, Ibrahim MAM, Ahmed WAM. The effect of AIDS peer health education on knowledge, attitudes, and practices of secondary school students in Khartoum, Sudan. AIMS Public Health. 2015; 2(4):718-726.

11. National Agency for the Control of AIDS (NACA). Nigeria prevalence rate. 2019. [Available at https://naca.gov.ng/nigeria-prevalence-rate/ [Accessedon 15 December, 2020]

12. Swadi H. Substance misuse in adolescents.Advance in Psychiatric Treatment. 2002; 6: 201-210.

13. Adedokun B, Olarinoye OM, Ilesanmi OS. HIV Prevalence and predictors among sexually active Nigerian youths.International Journal of Caring Sciences. 2016; 9(1):144-154.

14. Abia State Post Primary School Board. Students population. Abia State Government; 2019.

15. Ibirongbe D, Omede O, Babatunde O, Durowade K, Salaudeen AG, Akande T. Knowledge and use of emergency contraception among students of public secondary schools in Ilorin, Nigeria. Pan African Medical Journal. 2016; 23(10):11604.

16. World Medical Association. World Medical Association Declaration of Helsinki; Ethical principles for medical research involving human subjects. Journal of American Medical Association. 2013; 310:21912194. [CrossRef]

17. Bryne B. Structural equation modeling with AMOS. In Basic Concepts, Applications, and Programming. New York, NY, USA: Taylor \& Francis Group LLC; 2010.

18. Hirdy DB. (2007). Cultural practices contributing to the transmission of human immunodeficiency virus in Africa.Reviews of Infects Dis. 2007; 5:109-119.

19. Fenaughty AM, Massay HA, Fisher DG. HIV risk perception. Alaska Justice Forum. 2005;1 (4):13-25.

20. Hall GS. Adolescence. New York: Appleton; 2004.

21. Fazio RH. Attitude accessibility as a moderator of attitude perception and attitude behavior relation.Journal of Personality and Social Psychology. 2000; 51:508-514.

22. Hurlock E. Adolescence development. New York. McGraw Hill, $5^{\text {th }}$ ed; 2002.

23. Lamptey PR, Johnson JL, Khan M. (2006). The global challenge of HIV and AIDS.Population Bulletin. 2006; 61(1):3-21.

24. Martin S. Sex, population and politics. Madrid Editorial Fundamentos, $4^{\text {th }}$ ed., 12-13; 2009.

25. Moses S, Plummer FA. (2004).Health education, counselling and underlying cause of HIV epidemic in SubSaharan Africa.AIDS. 2004; 6:123-127.

26. World Health Organization.Progress on global access to HIV anti-retroviral therapy: an update.WHO, Geneva; 2005. 